\title{
Görüntü İşleme ve Makine Öğrenmesi Yöntemleri ile Baca Gazı Sıcaklığının Tahmin Edilmesi
}

\author{
Sedat Golgiyaz ${ }^{1 *}$, Muhammed Fatih Talu ${ }^{2}$, Cem Onat ${ }^{3}$ \\ ${ }^{1}$ Bilgisayar Mühendisliği Bölümü, Bingöl Üniversitesi,12000, Bingöl, Türkiye (ORCID: 0000-0003-0305-9713) \\ ${ }^{2}$ Bilgisayar Mühendisliği Bölümü, İnönü Üniversitesi,44280, Malatya, Türkiye (ORCID: 0000-0003-1166-8404) \\ ${ }^{3}$ Uçak Gövde-Motor Bölümü, Fırat Üniversitesi, 2300, Elâzı̆̆, Türkiye (ORCID: 0000-0002-2886-0470)
}

(Illk Geliş Tarihi 21 Mayıs 2019 ve Kabul Tarihi 1 Haziran 2019)

(DOI: 10.31590/ejosat.568348)

\begin{abstract}
ATIF/REFERENCE: Golgiyaz, S., Talu, M. F., \& Onat, C., (2019). Görüntü İşleme ve Makine Öğrenmesi Yöntemleri ile Baca Gaz1
\end{abstract} Sicaklığının Tahmin Edilmesi. Avrupa Bilim ve Teknoloji Dergisi, (16), 283-291.

$\ddot{\mathbf{O} z}$

Bu makalede, küçük ölçekli findık kömürü yakıtlı brülörde baca gazı sıcaklığı tahmini ile ilgili deneysel bir çalışma sunulmaktadır. Baca gazı sıcaklığı yakıt türüne göre belli bir aralıkta olması gerekir aksi durumda kazanda korozyona sebep olmaktadır. Bu çalışma kapsamında alev görüntüsünden öznitelikler elde edilmiştir. Bu öznitelikler ve DVR modeli ile baca gazı sıcaklığı tahmin edilmiştir. Alev görüntüsü CCD kamera ile alınmıştır. Aynı zamanda referans baca gazı sıcaklığı, baca gazı analizörü ile alınmıştır. Alev görüntüsü ve sıcaklık değeri aynı bilgisayara kaydedilmiştir. Alev görüntüsü gri seviye görüntüsüne çevrilerek öznitelikler elde edilmiştir. Öznitelikler elde edilirken alev görüntüsünün yoğunluk dağılımı kullanılmıştır. Bu işlem için iki tip dağılım kullanılmıştır. Birincisi görüntünün histogramı alınarak konumdan bağımsız yoğunluk dağılımının elde edilmesidir. İkincisi satır ve sütun toplamlarını kullanarak uzamsal yoğunluk dağılımının elde edilmesidir. Bu iki özniteliğin kombinasyonlarından elde edilen öznitelikler 6 çeşit DVR modeli ile gerçekleştirilmiştir. En iyi sonuçlar, her iki dağılımdan elde edilen özniteliklerin birlikte kullanıldığı öznitelik çıkarma yöntemi için kübik DVR modeli ile elde edilmiştir. Önerilen modelde baca sıcaklığı $\left(T{ }^{\circ} \mathrm{C}\right) \mathrm{R}=$ 0.97 doğruluk ile tahmin edilmiştir. Elde edilen sonuçlar baca gazı sıcaklığı ile alev görüntüsü arasında yüksek oranda bir iliş̧i olduğunu göstermektedir.

Anahtar Kelimeler: Baca gazı sıcaklığı tahmini, alev görüntüsü, destek vektör regresyon.

\section{Estimation of Flue Gas Temperature by Image Processing and Machine Learning Methods}

\begin{abstract}
This paper presents an experimental study on the flue gas temperature estimation in small-scale nut coal-fired boiler. The flue gas temperature must be within a certain range depending on the fuel type, otherwise it causes corrosion in the boiler. Within the scope of this study, features were obtained from flame image. The flue gas temperature was estimated with these features and the SVR model. The flame image was taken with a CCD camera. At the same time, the reference flue gas temperature was taken with the flue gas analyzer. The flame image and temperature are recorded on the same computer. Flame image is converted to gray scale image and features are obtained. The intensity distribution of the flame image was used when obtaining the features. Two types of distribution
\end{abstract}

"Sedat GOLGIYAZ: Bingöl Üniversitesi, Mühendislik Mimarlık Fakültesi, Bilgisayar Müh. Bölümü, Bingöl, Türkiye, ORCID: 00000003-0305-9713, Tel:90-426-2160012, sedatg@bingol.edu.tr 
were used for this process. The first is the histogram of the flame image to obtain a location independent intensity distribution. The second is to obtain a spatial intensity distribution using row and column sums. The attributes obtained from the combinations of these two type features were performed with 6 kinds of SVR models. The best results were obtained for the cubic SVR model for the feature extraction method in which the attributes obtained from both distributions were used together. In the proposed model the flue temperature $\left(\mathrm{T}^{\circ} \mathrm{C}\right)$ was estimated with $\mathrm{R}=0.97$ accuracy. The results show that there is a high correlation between the flue gas temperature and the flame image.

Keywords: Flue gas temperature estimation, flame image, support vector regression.

\section{Giriş}

Pek çok endüstriyel işlemde kazan, yakıttaki kimyasal enerjiyi yanma ile termal enerjiye dönüştüren ekipman olarak kullanılmaktadır. Aşındırıcı kül bileşenleri içeren kömürler (özellikle kuvars) ve yüksek baca gazı hızları (kısmen yakıt bileşimine bağlı olan) yakıt boruları ve kazan buhar borularında erozyonuna sebep olmaktadır. Kükürt ve klor gibi kömür kaynaklı bileşenler borularda korozyona yaparak arızalanmasına sebep olmaktadır. Teknolojideki ilerlemeye bağlı olarak emisyon mevzuatını sıkılaştırmak suretiyle işletmecilerden emisyonun azaltılması yönündeki beklentiler artmaktadır. Örneğin, Avrupa ve Kuzey Amerika'daki enerji santrallerinde baca gazı kükürt giderme, seçici katalitik indirgeme ve düşük $N O_{x}$ yakma sistemlerinin yaygın olarak yeniden yapılandırılması yasa koyucu tarafından istenmektedir (GoldsWorthy et al. 2013). Kükürt dioksit $\left(\mathrm{SO}_{2}\right)$ emisyonu, kömürdeki kükürt içeriğine bağlıdır, çünkü neredeyse kömür içerisindeki tüm kükürt yanma sırasında $\mathrm{SO}_{2}$ 'ye (bazısı $\mathrm{SO}_{3}$ 'e) oksitlenir. Yanma işlemi ile oluşan baca gazlarının, yakıt türüne ve yakıtın ihtiva ettiği kükürt miktarına bağlı olarak, belli bir sıcaklık aralığında olması gerekmektedir. Yakıt-hava oranının belli bir aralıkta olması kazan verimi açısından en önemli parametrelerden biridir. İdeal değerden fazla yakıt debisi, borulardaki kirlilik ve kazan ısıtma yüzeyinin yetersizliği gibi sebeplere bağlı olarak baca gazı sıcaklığı yükselmektedir. Kazanda baca gazı sıcaklığının yükselmesine bağlı olarak verim kaybı oluşmaktadır. Baca gazı sıcaklığının belli bir değerin altında düşmesi istenmemektedir. Düşük baca gazı sıcaklığında $\mathrm{SO}_{2}$ su buharı ile birleşerek sülfirik asite $\left(\mathrm{H}_{2} \mathrm{OSO}_{4}\right)$ dönüşür ve kazanda korozyona sebep olarak tahribatlara neden olur. Doğalgazda $130-150{ }^{\circ} \mathrm{C}$, sıv1 ve katı yakıtta $130-175{ }^{\circ} \mathrm{C}$ sıcaklık aralıkları baca gazı sıcaklığı için olması istenen değerlerdir. Kazanda yüksek baca gazı sıcaklığına yakıt hava oranı ayarlanarak veya borulara türbülatör takılarak müdahale edilmelidir. Baca gazı sıcaklığının her $20^{\circ}$ düşümü, enerji veriminde ortalama \%1 artışa sebep olmaktadır (Bilgin 2011).

Görüntü işleme uygulamalarının endüstride kullanım alanı gün geçtikçe artmaktadır(Golgiyaz et al. 2016; Peña et al. 2017). Alev görüntüsü ile icra edilen uygulamalar genel olarak 3 tip olmaktadır. Yanma sürecinin izlenmesi-kontrol edilmesi (GonzálezCencerrado et al. 2013; Hanbay et al. 2017; Wang et al. 2017), emisyon tahmini (Baek et al. 2001; Li et al. 2014; Wang et al. 2002) ve alev görüntüsünden sıcaklığının tahmin edilmesidir (Bonefacic et al. 2015; Lou et al. 2007; Xiangyu et al. 2018). Alev görüntüsü çalışmalarında genel olarak CCD(charge-coupled device) kamera kullanılmasına rağmen spektroskopik görüntüleme sistemi kullanan çalışmalarda bulunmaktadır (Krabicka et al. 2010; Li et al. 2016). Geleneksel CCD kameralar ucuz ve yaygın olmalarından dolayı tercih edilmektedir. Alev görüntüsü ile icra edilen çalışmalar değişik yakıt türleri ve değişik kapasite ve türdeki kazanlar için çeşitli metotlarla icra edilmiştir. Sadece geleneksel CCD kameralar ve görüntü yakalayıcı kullanılarak, alev görüntüleri doğrudan elde edilebilir. Alev görüntülerinin karakteristikleri, yanma performansındaki ölçüm kalitesi hakkında önemli bilgiler sağlar.

CCD kamera ile icra edilen uygulamalarda öznitelik çıkarmak için alevden doğal olarak yayılan radyal enerji sıklıkla kullanılmıştır (Huang et al. 2010; Liu et al. 2016; Zhou et al.1994). İlgili bir çalışmada gri alev görüntüsünün yoğunluk ortalaması Radyal Enerji Sinyali (RES) olarak alınmıştır (Huang et al. 2010; Zhou et al.1994). İlgili çalışmada çalışmada $N O_{x}$ emisyonu ve termal verimlilik gibi kazan ünitesi performansları incelenmiştir (Huang et al. 2010). Bir diğer çalışmada kömür yakıtlı alev karakteristiği yarı endüstriyel ölçekteki brülörde dijital görüntü işleme yoluyla çalışılmıştır (González-Cencerrado et al. 2012). İlgili çalışmada sıcaklık ve hava/yakıt oranıyla ilişkili parametrelerin parlaklık, titreşim ve dalgalanma genliği olduğu bildirilmiştir. Tespit edilen parametre bağımlılıklarını doğrulamak için farklı deneysel testler yapılması gerektiği vurgulanmıştır. Öznitelik elde etme yöntemi olarak (González-Cencerrado et al. 2012) nolu çalışmada önerilen yöntemdekine benzer öznitelikler kullanılarak farklı girdap koşulları için toz haline getirilmiş yakıtın karakteristiği alev görüntüsü işlenerek incelenmiştir (González-Cencerrado et al. 2013). Bir diğer çalışmada gri alev seviye görüntüsü ve güç çıkışının ortalama değerinden yani iki tip sensor verisinden RES hesaplanmıştır. Önerilen sistemde RES değeri ile brülör kömür yüklemesi kontrol edilmiştir (Liu et al. 2016). Görüntüden öznitelik çıkarmak yerine doğrudan piksel değerleri ile alev sıcaklığını tahmin eden çalışmalar da bulunmaktadır (Jiang et al. 2009; Xiangyu et al. 2016). Bu çalışmalarda önerilen sistem kamera parametrelerine bağımlı olmaları büyük bir dezavantajdır.

Alev görüntüsü ile icra edilen çalışmalardan da görüldüğü gibi alev görüntüsü ile baca gazı sıcaklığı arasında bir ilişki söz konusu olmaktadır. Çünkü alev görüntüsü ile alev sıcaklığının hesaplanması, emisyon değerlerinin tahmin edilmesi ve kazan veriminin kontrol edilmesi çalışmaları mevcuttur. Alev sıcaklığı, kazan emisyonu ve verimi ile baca gazı sıcaklığı arasında bir ilişki olmaktadır. Dolayısıyla alev görüntüsü ile baca gazı sıcaklığı arasında bir ilişki söz konusu olmaktadır. Bu ilişki bu çalışma kapsamında 
incelenmiştir. Literatürde sunulan öznitelik çıkarma yöntemlerinde alev yoğunluğu sıklıkla kullanılmasına rağmen konuma bağımlı alev yoğunluğu elde edilmemiştir. Dolayısıyla bu makale kapsamında sunulan uzamsal öznitelik elde etme yöntemi yanma karakteristiğini ifade etmede daha iyi olduğu deneysel çalışma sonucu elde edilen sonuçlardan da görülecektir.

Destek Vektör Makinaları (DVM) sınıflandırma problemlerinde başarılı bir şekilde kullanılmıştır. Aynı şekilde regresyon problemlerinde de Destek Vektör Regresyon (DVR) bir çok uygulama alanı bulmuştur (Qi et al. 2018). Bu çalışma kapsamında elde edilen öznitelikler ile baca gazı sıcaklığını tahmin etmek için DVR modeli kullanılmıştır. Yapay Sinir Ağı (YSA) ve DVR en yaygın kullanılan doğrusal olmayan regresyon modelleridir. YSA ile karşılaştırıldığında, istatistik öğrenme teorisine dayanan DVR yaklaşımı, hızlı öğrenme hızı, iyi genelleme yeteneği ve mükemmel gürültü toleransı özelliği avantajlarına sahiptir. Geçmişte, DVR'nin YSA'ya üstünlüğünü gösteren çalışmalar mevcuttur (Parveen et al. 2017; Quej et al. 2017; Wu et al. 2009). Bu çalışma kapsamında 6 adet DVR modeli için doğruluk kıyaslaması yapılarak nihai modele karar verilmiştir.

Kazan tipi ve kapasitesinden bağımsız olarak operasyonel mükemmellik için baca gazı sıcaklığının ölçülmesi ve sıcaklık kontrolü önemli olmaktadır. Hane 1sıtması, endüstri, ulaşım ve elektrik üretimi sektörlerinde kömür gelecekte de önemli bir enerji kaynağı olmaya devam edecektir (Conti et al. 2016). Mevcut baca gazı sıcaklığını ölçmek için termokupıl veya birçok ölçümün eşzamanlı alındığı baca gazı analizörleri kullanılmaktadır. Görüntü işleme sistemleri zaten kazanlarda alev sıcaklığının ölçülmesi, enerji verimliliğinin kontrol edilmesi ve emisyon tahmininde kullanılmaktadır. Önerilen sistem bu mevcuttaki sistemlerde baca gazı sıcaklığını alev görüntüsü ile ölçtüğü için maliyeti açısından avantajlıdır. Çünkü ek bir bileşene ihtiyaç olmadan baca ağzı sıcaklığı tahmin edilebilecektir. Baca gazı analizörü gibi sarf malzeme olmaması düzenli bakım gereksiniminin olmaması ve kesintisiz çalıştırılabildiğinden dolayı baca gazı analizörlerine göre daha avantajlıdır. Çünkü analizörler genellikle belli bir çalışma süresinden sonra cihazın çıkarılıp dinlenmesi gerekmektedir. Önerilen sistem mevcut küçük ölçekli ev tipi kazanlarda kullanılabileceği gibi, sistem geliştirilerek endüstride ve termik santraller gibi ileri düzey sistemlerde de yanma veriminin arttırılması ve korozyonun azaltılması için kullanılabilecektir.

\section{Deney Düzeneği}

Bu deney çalışması findık kömürü yakıtlı 85,000 kcal/h kapasiteli ev tipi kazan ile gerçekleştirilmiştir. Şekil 1'de deney boyunca elde edilen veriler;(a) $\mathrm{SO}_{2}$ emisyonu, (b) hava fazlalık katsayısı ve (c) oksijen konsantrasyonu verilmiştir. İlgili grafiklerden de görüldüğü hava fazlalık katsayısı aralı̆̆ı geniş (1-8) tutulmuştur.

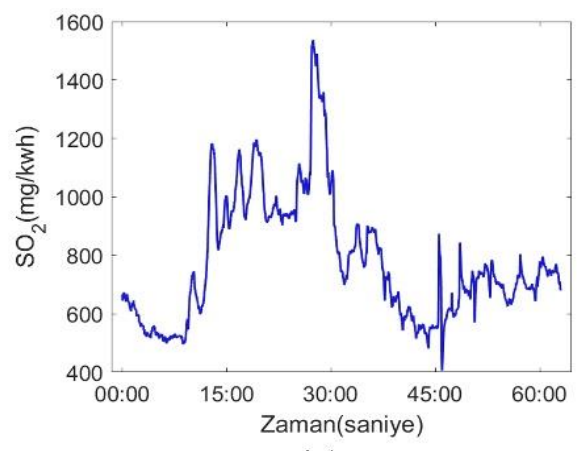

(a)

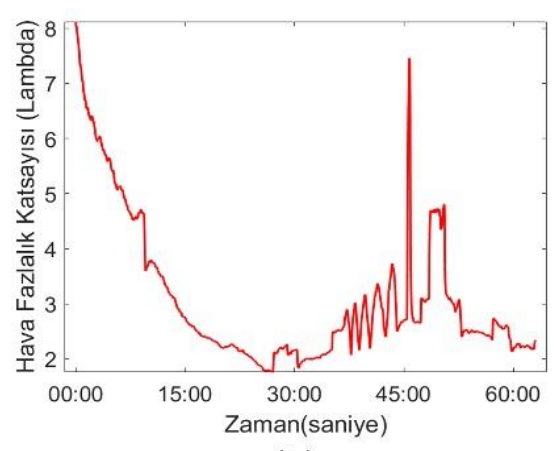

(b)

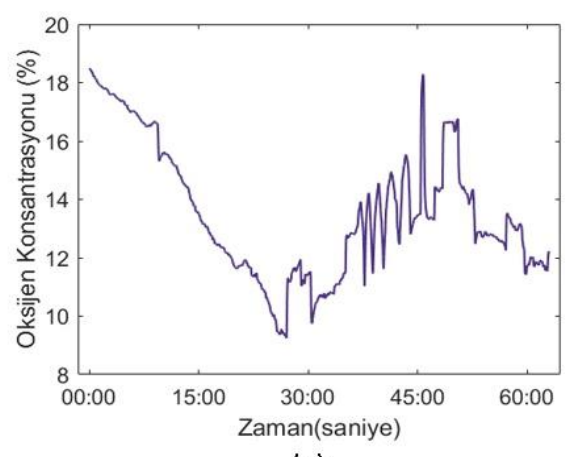

(c)

Şekil 1. Deneyin yapıldĭ̆ koşullar; (a) $\mathrm{SO}_{2}$ emisyonu, (b) hava fazlalık katsayısı ve (c) oksijen konsantrasyonu

Deney kazanına $10 \mathrm{~cm}$ çapında dairesel bir pencere açılmış ve yanma işlemi CCD kamera ile görüntülenmiştir. Gözetleme penceresi, kameranın zarar görmemesi ve ısı kaybının en aza indirilmesi için ısıya dayanıklı cam ile kapatılmıştır. Deney boyunca yanma işlemi CCD kamera ile 1200 × 1200 çözünürlükte yakalanmıştır. Kayıt işlemi 63 dakika boyunca yapılmıştır. Baca gazı emisyon cihazından kayıt periyodu saniyede bir olacak şekilde emisyon ölçümleri ve baca gazı sıcaklığı alınıp kaydedilmiştir. İlgilenilen alev görüntüsü kullanıcı tarafından $1160 \times 1160$ piksel olacak şekilde seçilmiştir. Bu şekilde 3780 adet baca gazı analizörü ölçümü ve alev görüntüsü aynı bilgisayara kaydedilmiştir. Baca gazı analizöründen elde edilen baca gazı sıcaklık değeri regresyon modelinin eğitilmesinde referans sıcaklık verisi olarak alınmıştır. Alev görüntüsü gri seviye görüntüsüne dönüştürülerek görüntü işleme teknikleriyle öznitelikler elde edilmiştir. Bu özniteliklerle daha az veri ile yanma sürecinin karakteristiği ifade edilmiştir. Bu çalışma sonucunda elde edilen sonuçlar literatürdeki diğer yöntemlerle doğruluk kıyaslanması yapılmıştır.

\section{Materyal ve Metot}

Kamera ile alınan alev görüntüsü gri seviye görüntüsüne çevrilerek yanma süreci ile ilgili öznitelikler elde edilmiştir. Renki alev görüntüsünün 3 bileşinin ortalaması alnıarak gri seviye alev görüntüsü elde edilmiştir. Öznitelikler elde edilirken gri alev görüntüsünün iki tip yoğunluk dağılımı kullanılmıştır. Birincisi 8 bit gri görüntünün 256 çubukluk histogramı alınarak konumdan 
bağımsız yoğunluk dağılımının elde edilmesidir. İkincisi her bir satır ve sütunun toplamını kullanarak uzamsal yoğunluk dağılımının elde edilmesidir. Bu iki özniteliğin kombinasyonlarından elde edilen öznitelikler regresyon modelinin eğitiminde kullanılmıştır. Bu şekilde anlık elde edilen görüntülerden özellikler elde edilerek DVR modeli vasıtasıyla baca gazı sıcaklığı tahmini yapılmıştır. DVR modelinde sadece anlık veriler ile anlık sıcaklı̆̆ı tahmini yapılmakta bu işlem için sadece görüntü öznitelikleri kullanılmaktadır.

\section{1. Önerilen Öznitelik Çıkarma Yöntemi}

Histogram sayısal bir verinin dağılımını gösteren bir sütun grafiğidir. Görüntünün histogramı denilince 8 bitlik bir görüntü için 256 adet yoğunluk seviyesinden bahsedilmektedir. Görüntünün histogramı ile bu 256 adet yoğunluk seviyesinin, görüntüdeki frekans dağılımından bahsedilmektedir. Görüntünün histogramı; görüntünün iyileştirilmesi, görüntünün sınıflandırılması ve bölütleme problemleri gibi alanlarda kullanım alanı bulmaktadır. Bu çalışma kapsamında görüntü histogramı $H$ ile temsil edilecektir.

Alevin gri seviye görüntüsü $I_{m \times n}$ olmak üzere uzamsal yoğunluk dağılımı, satır (1) ve sütun (2) toplamları denklemleri aşağıdaki gibi hesaplanabilir.

$X_{i}^{\prime}=\sum_{\mathrm{j}=1}^{\mathrm{n}} I_{i j}$

$Y_{j}^{\prime}=\sum_{\mathrm{i}=1}^{\mathrm{m}} I_{i j}$

$X^{\prime}$ ve $Y^{\prime}$ öznitelikleri ile yanma işlemi hakkında uzamsal bilgi elde edilmektedir. Önerilen sistem eğitilirken $X^{\prime}, Y^{\prime}$ ve $H^{\prime}$ nin kombinasyonları kullanılmıştır.

\subsection{Görüntü Momentleri}

Görüntü momentleri parlaklık ve yoğunluk değerlerini temsil etmek için kullanılan özniteliklerdir. Görüntünün 4 momenti olan ortalama, standart sapma, çarpıklık ve basıklık literatürde yoğun olarak kullanılmıştır. Görüntünün momentlerinden öznitelik elde edilirken çoğu zaman görüntü gri seviye resme çevrilmektedir. Alev görüntüsünün 4 momentini hesaplamak için denklem (3)'de ortalama, (4)'te standart sapma, (5)'te çarpıklık ve (6)'da basıklık denklemleri verilmiştir.

- $\quad$ Birinci Moment - Ortalama:

$\mu_{k}=\frac{1}{m x n} \sum_{i=1}^{m} \sum_{j=1}^{n} k_{i, j}$

- İkinci Moment - Standart Sapma:

$\sigma_{k}=\frac{1}{m x n} \sum_{i=1}^{m} \sum_{j=1}^{n}\left(k_{i, j}-\mu_{k}\right)^{2}$

- Üẹüncü Moment - Çarpıklık:

$\gamma s_{k}=\frac{1}{m x n} \sum_{i=1}^{m} \sum_{j=1}^{n}\left(\frac{k_{i, j}-\mu_{k}}{\sigma_{k}}\right)^{3}$

- Dördüncü Moment - Basıklık:

$\gamma k_{k}=\frac{1}{m x n} \sum_{i=1}^{m} \sum_{j=1}^{n}\left(\frac{k_{i, j}-\mu_{k}}{\sigma_{k}}\right)^{4}-3$

\subsection{Destek Vektör Regresyon (DVR)}

Alev görüntüsünden elde edilen öznitelikler ile baca gazı sıcaklığını tahmin etmek için DVR modeli kullanılmıştı. DVM ilk olarak 1992'de Vladimir Vapnik ve arkadaşları tarafından tanımlanmış, sınıflandırma ve regresyon problemleri için popüler bir makine öğrenmesi yöntemidir (Vapnik 2000). DVR parametrik olmayan bir teknik olarak kabul edilir, çünkü çekirdek fonksiyonlarına dayanmaktadır. DVR ve YSA regresyon problemleri için en yaygın kullanılan doğrusal olmayan modellerdir. DVR eğitim verisi setinde tahmin değişkenlerini ve referans cevap değerlerini bulunur. Amaç, her eğitim noktası $\boldsymbol{x}$ için $\varepsilon$ 'dan büyük olmayan bir değerle $\boldsymbol{y}_{\boldsymbol{n}}$ 'den sapan ve mümkün olduğu kadar düz olan bir $\boldsymbol{f}(\boldsymbol{x})$ fonksiyon bulmaktır. Şekil 2'de önerilen yapının genel şeması verilmiştir.

\subsubsection{Doğrusal DVR}

Farz edelim ki $x_{n}, y_{n}$ gözlemlenen yanıt değerlerine sahip çok değişkenli $\mathrm{N}$ adet gözlem verisinden oluşan bir veri setidir. Doğrusal fonksiyonu bulmak için (7) deki denklem kullanılsın

$f(x)=x^{\prime} \beta+b$

Bu fonksiyonda $f(x)$ bulmak için minimum norm değeri $\left(\|\beta\|=\beta^{\prime} \beta\right)$ ile bulunur. Bu fonksiyonu minimize etmek için dışbükey bir optimizasyon problemi olarak denklem (8)'deki gibi ifade edilir. 


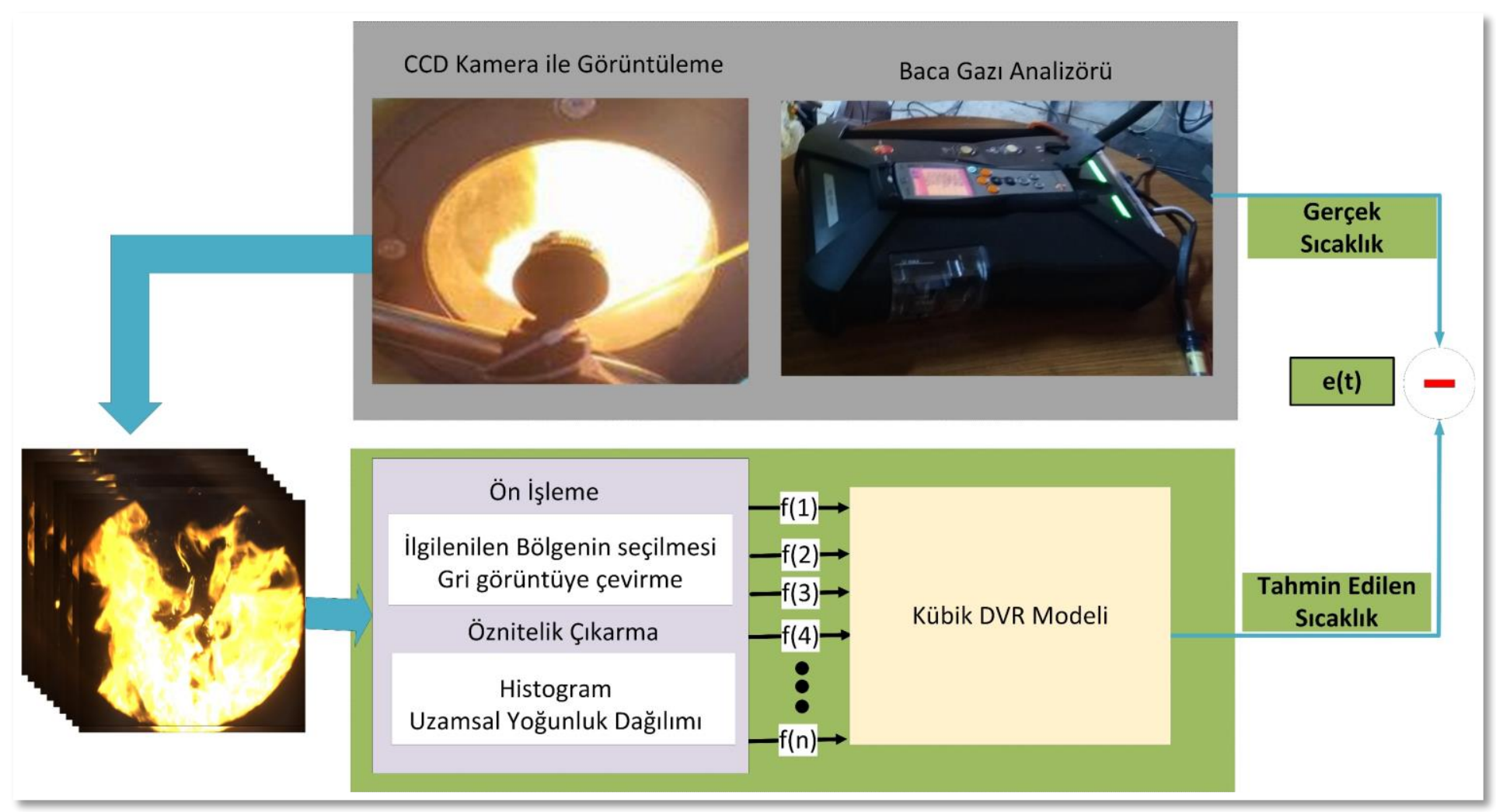

Şekil 2. Önerilen yapinin genel şeması

Denklem (8) verilen şartı yerine getirecek bir $f(x)$ fonksiyonunun bulunmaması mümkündür. Bu durumda denklemi çözülebilir kılmak için, her nokta için $\xi_{n}$ ve $\xi_{n}^{*}$ gevşek değişkenleri kullanılır. Gevşek değişkenler regresyon hatalarının $\xi_{n}$ ve $\xi_{n}^{*}$ değerlerine kadar var olmasına izin verir. Gevşek değişkenlerin dahil edilmesi, primal formül olarak da bilinen amaç fonksiyonuna dönüşümü sağlar (Vapnik 2000). Amaç fonksiyonu (9)'da verilmiştir.

$\mathrm{J}(\beta)=\frac{1}{2}\|\beta\|+C \sum_{n=1}^{N}\left(\xi_{n}+\xi_{n}^{*}\right)$

Burada C sabiti kutu kısııtıdır, epsilon marjının $(\varepsilon)$ dışında kalan gözlemlere uygulanan cezayı kontrol eden pozitif bir sayısal değerdir ve aşırı öğrenmenin önlenmesini sağlar. Bu çalışma kapsamında önerilen tüm modellerde $\mathrm{C}$ sabiti ölçeklendirilmiş gözlenen değerlerin 1.349 ile bölünmesiyle elde edilmiştir. Epsilon ise ölçeklendirilmiş gözlenen değerlerin 13.49 ile bölünmesiyle elde edilen değer olarak alınmıştır.

\subsubsection{Doğrusal olmayan DVR}

Bazı regresyon problemleri doğrusal bir model kullanılarak yeterince tanımlanamaz. Böyle bir durumda, Lagrange formülasyonu doğrusal olmayan fonksiyonların için kullanılabilir. $x 1^{\prime} x 2$ 'nin iç çarpımı yerine doğrusal olmayan bir çekirdek fonksiyonu $G(x 1, x 2)=\langle\varphi(x 1), \varphi(x 2)\rangle$ ile değiştirerek, x’i yüksek boyutlu bir uzaya taşıyan bir dönüşüm kullanılır. Çekirdek fonksiyonları, doğrusal ayrımı gerçekleştirmeyi mümkün kılmak için verileri daha yüksek boyutlu bir öznitelik uzayına dönüştürür. Bu çalışma kapsamında doğrusal, kübik, ikinci dereceden, orta gauss, ince gauss ve kaba gauss modeli olmak üzere 6 adet doğrusal olmayan DVR modeli kullanılmıştır. Doğruluk kıyaslaması yapılarak nihai modele karar verilmiştir. Bunlardan doğrusal DVR'de doğrusal (iç çarpım) çekirdek fonksiyonu (10), kübik ve ikinci dereceden DVR'de polinom çekirdek fonksiyonları (11) ve ince, orta ile kaba gauss DVR modellerinde gauss çekirdek fonksiyonu (12) kullanılmıştır.

$G\left(x_{j}, x_{k}\right)=x_{j}^{\prime} x_{k}$

$G\left(x_{j}, x_{k}\right)=\left(1+x_{j} x_{k}\right)^{q}$,

$\left.G\left(x_{j}, x_{k}\right)=\exp \left(-\left\|x_{j}-x_{k}\right\|\right)^{2}\right)$ 
Bu durumda yeni değerleri tahmin etmek için kullanılan fonksiyon denklem (13)'te verilmiştir.

$f(x)=\sum_{n=1}^{N}\left(\alpha_{n}-\alpha_{n}^{*}\right)<\varphi(x 1), \varphi(x 2)>+$ b veya $f(x)=\sum_{n=1}^{N}\left(\alpha_{n}-\alpha_{n}^{*}\right) \mathrm{G}\left(\mathrm{x}_{\mathrm{n}}, \mathrm{x}\right)+b$

Önerilen sistem de çapraz doğrulama yaklaşımı kullanılmıştır. Çapraz doğrulama işlemi için tüm modellerde veri seti 5 parçaya bölünmüştür. Çekirdek fonksiyonu genişliği giriş verisine göre otomatik hesaplanmıştır.

\subsection{DVR Modeli için Performans Kriterleri}

Görüntü öznitelikleri ile elde edilen verileri kullanıp DVR modeliyle elde edilen sonuçların referans verilerle kıyaslanıp performans verileri için korelasyon katsayısı (R) ve kök ortalama kare hata (RMSE) ölçütleri kullanılmışıı. RMSE (13) ve R (14) değerleri aşağıdaki gibi tanımlana bilir. Verilen sonuçlar 5 adet çapraz doğrulama işlemi için kullanılan tüm veriler için elde edilen sonuçlardır.

$\operatorname{RMSE}=\left[\frac{1}{N} \sum_{\mathrm{i}=1}^{\mathrm{N}}\left(\mathrm{D}_{\mathrm{i}}-\widetilde{\mathrm{D}}_{\mathrm{i}}\right)^{2}\right]^{1 / 2}$

$\mathrm{R}=\left[1-\frac{\sum_{\mathrm{i}=1}^{\mathrm{N}}\left(\mathrm{D}_{\mathrm{i}}-\widetilde{\mathrm{D}}_{\mathrm{i}}\right)^{2}}{\sum_{\mathrm{i}=1}^{\mathrm{N}}\left(\mathrm{D}_{\mathrm{i}}-\overline{\mathrm{D}}\right)^{2}}\right]^{1 / 2}$

Burada $D_{i}$ değeri tekil baca gazı sıcaklık değerini, $\bar{D}$ ise tüm $D_{i}$ değerlerinin ortalamasını ve $\widetilde{D}_{i}$ ise DVR modeli sonucunda hesaplanan baca gazı sıcaklık değerini ifade etmektedir.

\section{Bulgular ve Tartışma}

Alev görüntüsü ile DVR modeli arasındaki ilişsi 6 çeşit DVR modeli için incelenmiştir. En iyi modele bu modellerin başarım performasnlarına göre karar verilmiştir. Tablo 1'de ilgili DVR modelleri için önerilen öznitelik çıkarma yöntemlerinin farklı kombinasyonları için başarımları verilmiştir.

Tablo 1. Önerilen Öznitelik çıkarma yöntemlerinin değişik varyasyonları için DVR modelleri başarımları

\begin{tabular}{|c|c|c|c|c|c|c|c|c|c|c|c|c|c|}
\hline & & \multicolumn{12}{|c|}{ DVR Yöntemi } \\
\hline & & \multicolumn{2}{|c|}{ Kübik } & \multicolumn{2}{|c|}{ İnce Gauss } & \multicolumn{2}{|c|}{$\begin{array}{c}\text { İkinci } \\
\text { Dereceden }\end{array}$} & \multicolumn{2}{|c|}{ Orta Gauss } & \multicolumn{2}{|c|}{ Doğrusal } & \multicolumn{2}{|c|}{ Kaba Gauss } \\
\hline & & $\mathrm{R}$ & RMSE & $\mathrm{R}$ & RMSE & $\mathrm{R}$ & RMSE & $\mathrm{R}$ & RMSE & $\mathrm{R}$ & RMSE & $\mathrm{R}$ & RMSE \\
\hline \multirow{7}{*}{ 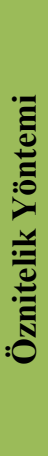 } & $H X^{\prime} Y^{\prime}$ & 0,97 & 8,12 & 0,96 & 8,49 & 0,96 & 9,09 & 0,86 & 16,39 & 0,84 & 17,15 & 0,76 & 20,80 \\
\hline & $H X^{\prime}$ & 0,95 & 10,25 & 0,93 & 11,61 & 0,93 & 11,65 & 0,81 & 18,74 & 0,78 & 19,97 & 0,74 & 21,72 \\
\hline & $X^{\prime} Y^{\prime}$ & 0,94 & 11,38 & 0,95 & 10,08 & 0,93 & 11,39 & 0,83 & 17,52 & 0,80 & 19,13 & 0,76 & 20,97 \\
\hline & $H Y^{\prime}$ & 0,93 & 11,85 & 0,92 & 12,75 & 0,93 & 11,68 & 0,83 & 18,34 & 0,83 & 17,59 & 0,67 & 24,38 \\
\hline & $X^{\prime}$ & 0,88 & 15,78 & 0,90 & 13,98 & 0,87 & 15,34 & 0,78 & 19,83 & 0,74 & 21,31 & 0,72 & 22,22 \\
\hline & $Y^{\prime}$ & 0,84 & 19,79 & 0,87 & 16,09 & 0,88 & 14,97 & 0,78 & 20,19 & 0,75 & 21,04 & 0,69 & 24,44 \\
\hline & $H$ & 0,81 & 19,53 & 0,70 & 22,45 & 0,84 & 17,30 & 0,58 & 25,92 & 0,64 & 24,37 & 0,46 & 28,74 \\
\hline
\end{tabular}

Tablo 1'de görüldüğü gibi baca gazı sıcaklığı ve alev görüntüsü arasındaki en yüksek ilişki uzamsal dağılım özniteliklerinin her ikisi ve görüntü histogramının birlikte kullanıldığı öznitelik çıkarma yöntemi için kübik DVR modeli için bulunmuştur. İlgili model için baca gazı sıcaklığı ve alev görüntüsü arasında $R=0.97$ ilişki bulunmuş ve $R M S E=8,12$ olarak hesaplanmıştır. Önerilen ideal kübik DVR modeli için gerçek ve tahmin edilen baca gazı sıcaklığı grafiksel olarak Şekil 3 ’te verilmiştir.

Baca gazı sıcaklığı tahmininde son araştırmada önerilen öznitelik çıkarma yapısı ile literatürdeki diğer öznitelik çıkarma yöntemleri aynı veri seti ve 6 çeşit DVR modeli için gerçekleştirilmiştir. Burada hedeflenen sadece öznitelik çıkarma yöntemlerinin performansını kıyaslamaktır. Diğer yöntemlerin sonuçları verilirken 6 çeşit DVR modelinden sadece en iyi DVR modeli için sonuç verilecektir. 


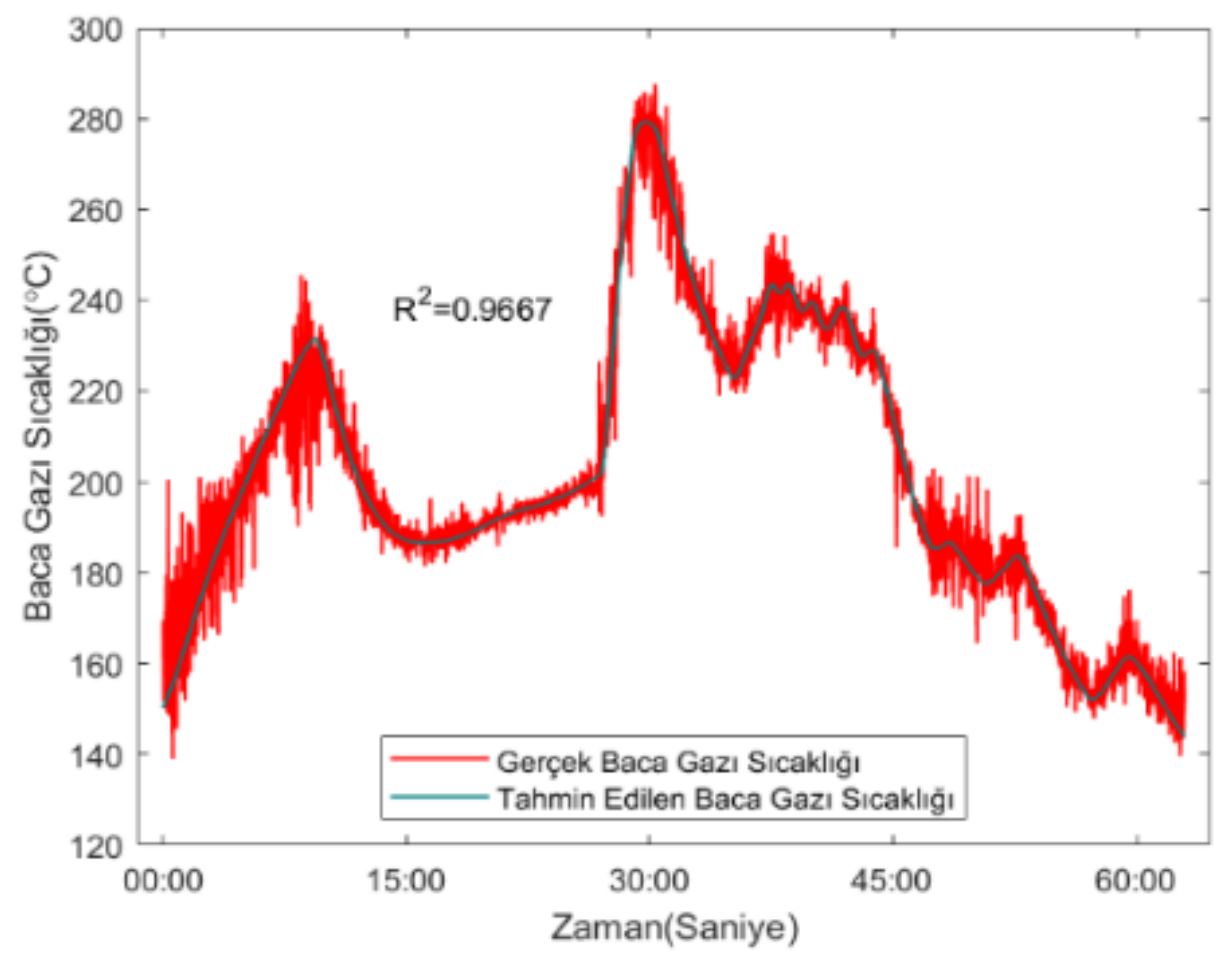

Şekil 3. Gerçek ve kübik DVR modelinin tahmin ettiği baca gazı sıcaklı̆̆

Tablo 2'den de görüldüğü gibi önerilen öznitelik elde etme yöntemi diğer yöntemlere göre daha başarıll olmuştur. Tablo 1 ve 2 birlikte değerlendirildiğinde uzamsal yoğunluk dağılımın özniteliklerinin alevin karakteristiğini ortaya koymada çok etkin olduğu sonucuna ulaşılabilir.

Tablo 2. Önerilen öznitelik çıkarme yöntemi ve diğer yöntemlerin kıyaslanması

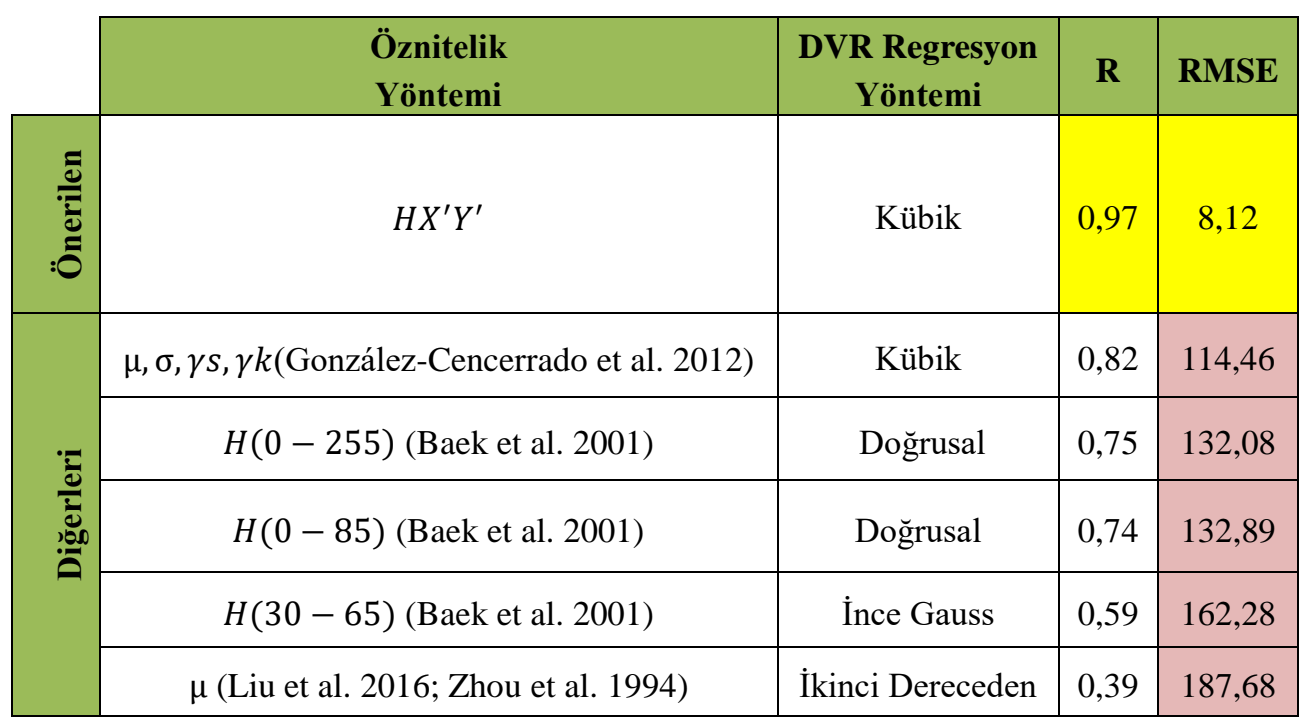

\section{Sonuç ve Öneriler}

$\mathrm{Bu}$ deneysel çalışmada alev görüntüsünün uzamsal yoğunluk dağılımının alev karakteristiğini iyi derecede yansıtttı̆g 1 gösterilmiştir. Deneysel çalışmada baca gazı sıcaklı̆̆ı tahmini yüksek olup yanma kontrol sistemlerinde kullanılabileceğini göstermiş̧ir. Doğrusal olmayan alev görüntüsü öznitelikleri ile baca gazı sıcaklı̆ğ arasında ilişki ortaya konulurken kübik DVR modeli yüksek ilişki oranıyla öne çıkmıştır. Elde edilen deneysel sonuçlar alev görüntüsü ve DVR modeli ile baca gazı sıcaklığının 
tahmin edilebileceğini göstermektedir. CCD kameralar zaten emisyon kontrolü ve kazanın izlenip kontrol edilmesi için kullanıldığı için önerilen yöntem bu sistemlere baca gazı sıcaklığı tahmini bileşenini eklemeyi mümkün kılmaktadır. Böylece yüksek baca gazı sıcaklığından kaynaklanan verim düşümü önlenerek hem kazan verimi arttırıla bilir hem de düşük sıcaklıkta oluşan $\mathrm{H}_{2} \mathrm{SO}_{4}$ oluşumu önlenerek kazanda korozyona sebep olmayacak şekilde ayarlama yapılmasına imkân verir. İleride farklı kapasitedeki kazanlar ile yapılacak çalışmalarda alev görüntüsü ile baca gazı sıcaklığı arasındaki ilişkinin kazanın kapasitesinden nasıl etkilediği araştııılabilir.

\section{Teşekkür}

Bu çalışma, Türkiye Bilimsel ve Teknolojik Araştırma Kurumu (TÜBİTAK, Proje no: 117M121) ve MIMSAN AŞ tarafından desteklenmiştir.

\section{Kaynakça}

Baek, W. B., S. J. Lee, S. Y. Baeg, and C. H. Cho. 2001. "Flame Image Processing \& Analysis for Optimal Coal Firing of Thermal Power Plant." \{ISIE 2001: IEEE International Symposium on Industrial Electronics Proceedeing, Vols I-III\} \{928-931\}.

Bilgin, Abdullah. 2011. "Kazanlarda Enerji Verimliliği ve Emisyonlar." Pp. 59-65 in VIII. Ulusal Tesisat Mühendisliği Kongresi. İzmir: TMMOB Makina Mühendisleri Odası.

Bonefacic, Igor, Paolo Blecich, I. Bonefačić, and -P Blecich. 2015. Two-Color Temperature Measurement Method Using BPW34 PIN Photodiodes. Vol. 35.

Conti, John, Paul Holtberg, Jim Diefenderfer, Angelina LaRose, James T. Turnure, and Lynn Westfall. 2016. International Energy Outlook 2016 With Projections to 2040.

GoldsWorthy, P., D. J. Eyre, and E. On. 2013. Value-in-Use (VIU) Assessment for Thermal and Metallurgical Coal. Vol. 2.

Golgiyaz, Sedat, Muhammed Fatih Talu, and Cem Onat. 2016. "Estimation of Excess Air Coefficient for Automated Feed Coal Burners with Image-Based Gauss Model.” Pp. 528-31 in International Conferece on Artificial Intelligence and Data Processing, IDAP'16. Malatya-Turkey.

González-Cencerrado, A., A. Gil, and B. Peña. 2013. "Characterization of PF Flames under Different Swirl Conditions Based on Visualization Systems." Fuel 113:798-809.

González-Cencerrado, A., B. Peña, and A. Gil. 2012. "Coal Flame Characterization by Means of Digital Image Processing in a SemiIndustrial Scale PF Swirl Burner.” Applied Energy 94:375-84.

Hanbay, Kazim, Sedat Golgiyaz, and Muhammed Fatih Talu. 2017. "Real Time Fabric Defect Detection System on Matlab and C++/Opencv Platforms." Pp. 1-8 in 2017 International Artificial Intelligence and Data Processing Symposium (IDAP). IEEE.

Huang, Benyuan, Zixue Luo, and Huaichun Zhou. 2010. "Optimization of Combustion Based on Introducing Radiant Energy Signal in Pulverized Coal-Fired Boiler.” Fuel Processing Technology 91(6):660-68.

Jiang, Zhi-Wei Wei, Zi-Xue Xue Luo, and Huai-Chun Chun Zhou. 2009. "A Simple Measurement Method of Temperature and Emissivity of Coal-Fired Flames from Visible Radiation Image and Its Application in a CFB Boiler Furnace." Fuel 88:980-87.

Krabicka, Jan, Gang Lu, and Yong Yan. 2010. "A Spectroscopic Imaging System for Flame Radical Profiling.” Pp. 1387-91 in 2010 IEEE Instrumentation \& Measurement Technology Conference Proceedings. IEEE.

Li, Nan, Gang Lu, Xinli Li, and Yong Yan. 2014. "Prediction of Pollutant Emissions of Biomass Flames Using Digital Imaging, Contourlet Transform and Radial Basis Function Network Techniques." Conference Record - IEEE Instrumentation and Measurement Technology Conference 697-700.

Li, Nan, Gang Lu, Xinli Li, and Yong Yan. 2016. "Prediction of NOx Emissions from a Biomass Fired Combustion Process Based on Flame Radical Imaging and Deep Learning Techniques.” Combustion Science and Technology 188(2):233-46.

Liu, Zhuwei, Shu Zheng, Zixue Luo, and Huaichun Zhou. 2016. "A New Method for Constructing Radiative Energy Signal in a CoalFired Boiler.” Applied Thermal Engineering 101:446-54.

Lou, Chun, Huai Chun Zhou, Peng Feng Yu, and Zhi Wei Jiang. 2007. "Measurements of the Flame Emissivity and Radiative Properties of Particulate Medium in Pulverized-Coal-Fired Boiler Furnaces by Image Processing of Visible Radiation." Proceedings of the Combustion Institute 31 II:2771-78.

Parveen, Nusrat, Sadaf Zaidi, and Mohammad Danish. 2017. "Development of SVR-Based Model and Comparative Analysis with MLR and ANN Models for Predicting the Sorption Capacity of Cr(VI)." Process Safety and Environmental Protection 107:42837.

Peña, B., C. Bartolomé, and A. Gil. 2017. "Analysis of Thermal Resistance Evolution of Ash Deposits during Co-Firing of Coal with Biomass and Coal Mine Waste Residues." Fuel 194:357-67.

Qi, Minfang, Huageng Luo, Peijun Wei, and Zhongguang Fu. 2018. "Estimation of Low Calorific Value of Blended Coals Based on Support Vector Regression and Sensitivity Analysis in Coal-Fired Power Plants." Fuel 236:1400-1407.

Quej, Victor H., Javier Almorox, Javier A. Arnaldo, and Laurel Saito. 2017. "ANFIS, SVM and ANN Soft-Computing Techniques to Estimate Daily Global Solar Radiation in a Warm Sub-Humid Environment." Journal of Atmospheric and Solar-Terrestrial Physics 155:62-70.

Vapnik, Vladimir N. 2000. The Nature of Statistical Learning Theory. Springer.

Wang, F., X. J. Wang, Z. Y. Ma, J. H. Yan, Y. Chi, C. Y. Wei, M. J. Ni, and K. F. Cen. 2002. "The Research on the Estimation for the NOxemissive Concentration of the Pulverized Coal Boiler by the Flame Image Processing Technique.” Fuel 81(16):2113-20. 
Wang, Zhichao, Min Liu, Mingyu Dong, and Lian Wu. 2017. "Riemannian Alternative Matrix Completion for Image-Based Flame Recognition." IEEE Transactions on Circuits and Systems for Video Technology 27(11):2490-2503.

Wu, Feng, Hao Zhou, Tao Ren, Ligang Zheng, and Kefa Cen. 2009. "Combining Support Vector Regression and Cellular Genetic Algorithm for Multi-Objective Optimization of Coal-Fired Utility Boilers.” Fuel 88:1864-70.

Xiangyu, Zhang, Zheng Shu, Zhou Huaichun, Zhang Bo, Wang Huajian, and Xu Hongjie. 2016. "Simultaneously Reconstruction of Inhomogeneous Temperature and Radiative Properties by Radiation Image Processing." International Journal of Thermal Sciences 107:121-30.

Xiangyu, Zhang, Lu Xu, Yang yu, Zhang Bo, and Xu Hongjie. 2018. "Temperature Measurement of Coal Fired Flame in the Cement Kiln by Raw Image Processing." Measurement: Journal of the International Measurement Confederation.

Zhou, H., Han, C. 1994. "An Exploratory Investigation of the Computer-Based Control of Utility Coal-Fired Boiler Furnace Combustion." Pp. 111-16 in J. Eng. Therm. Energy Power. 